\title{
Basal-Like Subgroup is Associated with Younger Age, Increased Expression of Androgen Receptor, and Worse Prognosis, while Non-basal-like Subtype is Associated with Higher BMI in Triple-Negative Breast Cancer Patients
}

\author{
Ibnu Purwanto ${ }^{1, *}$, Didik Setyo Heriyanto ${ }^{2}$, Ahmad Ghozali $^{2}$, Irianiwati Widodo², \\ Iwan Dwiprahasto ${ }^{3}$, Teguh Aryandono ${ }^{4}$, Sofia Mubarika Haryana ${ }^{5}$ \\ ${ }^{1}$ Division of Hematology and Medical Oncology, Department of Internal Medicine, Faculty of Medicine, Public Health, and Nursing, \\ Universitas Gadjah Mada/Dr Sardjito Hospital, Jl. Farmako, Sekip Utara, Yogyakarta, Indonesia \\ ${ }^{2}$ Department of Anatomical Pathology, Faculty of Medicine, Public Health, and Nursing, Universitas Gadjah Mada/Dr Sardjito Hospital, Jl. Farmako, \\ Sekip Utara, Yogyakarta, Indonesia \\ ${ }^{3}$ Department of Clinical Pharmacology, Faculty of Medicine, Public Health, and Nursing, Universitas Gadjah Mada/Dr Sardjito Hospital, Jl. Farmako, \\ Sekip Utara, Yogyakarta, Indonesia \\ ${ }^{4}$ Department of Surgical Oncology, Faculty of Medicine, Public Health, and Nursing, Universitas Gadjah Mada/Dr Sardjito Hospital, Jl. Farmako, \\ Sekip Utara, Yogyakarta, Indonesia \\ ${ }^{5}$ Department of Histology and Cell Biology, Faculty of Medicine, Public Health, and Nursing, Universitas Gadjah Mada/Dr Sardjito Hospital, \\ Jl. Farmako, Sekip Utara, Yogyakarta, Indonesia \\ *Corresponding author. E-mail: ibnu.purwanto.md@gmail.com
}

Received date: May 31, 2020; Revised date: Sep 7, 2020; Accepted date: Sep 11, 2020

\section{Abstract}

ACKGROUND: Triple-negative breast cancer (TNBC) represents a heterogenous disease which differ in characteristic, treatment response and prognosis. We aim to perform in-depth analysis on the clinicopathologic feature and the prognostic value of basallike and non-basal-like TNBC patients in an Indonesian tertiary hospital.

METHODS: We retrospectively included patients diagnosed with TNBC between 2014-2017. Clinical variables were collected from medical record. Expression of epidermal growth factor receptor (EGFR), cytokeratin 5/6 (CK5/6), p53 mutant and androgen receptor (AR) were examined by using immunohistochemistry (IHC).

RESULTS: We included 67 subjects, $67.1 \%$ were basal-like and the remaining $32.9 \%$ were non-basal-like, with mean age of 51 years old, $59.7 \%$ subjects had BMI $<25$ and $40.3 \%$ subjects had $\mathrm{BMI} \geq 25 ; 16.4 \%, 65.7 \%$, and $17.9 \%$ subjects presented with early stage, locally advanced stage, and distant metastasis respectively; $\mathrm{T}<5 \mathrm{~cm}$ was found in $29.9 \%$ subjects, while $70.1 \%$ subjects had $\mathrm{T} \geq 5 ; 67.2 \%$ subjects presented with $\mathrm{N}$-, while $32.8 \%$ subjects were $\mathrm{N}+$. The most common histological type was infiltrating ductal $(82 \%$ of subjects). P53 mutant and AR expressions were positive in $44.8 \%$ and $15 \%$ subjects, respectively. Basal-like subtype presented with younger age at and had higher expression of $\mathrm{AR}$, while non-basal-like subtype is associated with $\mathrm{BMI} \geq 25(p<0.05)$. Basal-like subjects had shorter overall survival (23.9 months (95\% CI: 21.9-25.9) vs. 26.1 months (95\% CI: 23-29.2).

CONCLUSION: Basal-like subtype is associated with worse prognosis, younger age at diagnosis and increased expression of AR, while non-basal-like subtype is associated with higher BMI in Indonesian TNBC.

KEYWORDS: TNBC, subtype, basal-like, young age, Indonesia

Indones Biomed J. 2020; 12(4): 349-54

\section{Introduction}

Breast cancer is still the most common type of malignancy in female with annual incidence of 200,000 cases worldwide with estimated incidence of 18.6/100,000 females annually in Indonesia.(1,2) Triple-negative breast cancer (TNBC), lacks obvious therapeutic target and is historically associated with poor prognosis.(3) Genetic profiling has improved our understanding on the heterogeneity of breast cancer, 
including $\mathrm{TNBC}$, thus allowing us to deconstruct TNBC into a spectrum of subtypes which differ in cellular origin, tumor characteristic, response towards therapy, and most importantly, prognosis.(4) Triple-negative breast cancer can be broadly classified into basal-like and non-basallike subtypes according to cytokeratin 5/6 (CK5/6) and epidermal growth factor receptor (EGFR) expression. Basallike subtype is generally associated with more aggressive tumor characteristic, albeit better response towards systemic chemotherapy.(3) Nevertheless, genetic variation exists in TNBC, proven by its wide intrinsic molecular variation and varied survival rate reported by many studies.(5)

Several biomarkers have been extensively studied to help clinician to stratify prognosis and determine potential treatment modalities for TNBC patients, including androgen receptor (AR) and p53 mutant. Expression of $A R$ and p53 mutant have been associated with worse prognosis and worse response towards systemic chemotherapy in TNBC.(6-8) However, these studies usually consider TNBC as a single disease, thus expression pattern and clinical significance of these biomarkers among TNBC subtypes is not yet adequately studied. This paper aims to perform in-depth analysis on the clinicopathologic feature and prognostic value of basal-like and non-basal-like TNBC patients in an Indonesian tertiary hospital. To the best of our knowledge, this is the first of such study involving Indonesian patients.

\section{Methods}

This was a retrospective study conducted at Dr. Sardjito Hospital, Yogyakarta, Indonesia. We consecutively included stage I-IV TNBC patients diagnosed between 2014-2017. Out of 272 detected patients, 205 patients were excluded due to incomplete data, leaving 67 patients included in this study. Clinical data was retrieved from medical records. This study has been approved by the institutional review board of the Ethics Committee Faculty of Medicine, Public Health, and Nursing, Universitas Gadjah Mada/ Dr. Sardjito Hospital, Yogyakarta, Indonesia with approval numbers: KE/ FK/0751/EC/2018 (first approval) and KE/0286/03/2020 (latest update).

\section{Immunohistochemistry Analysis}

Tumor samples were obtained from formalin-fixed paraffinembedded (FFPE) tissue stored at the Department of Anatomical Pathology, Dr. Sardjito General Hospital, Yogyakarta; Waskhita Laboratory, Yogyakarta; Panti Rapih General Hospital, Yogyakarta; and CITO Laboratory,
Yogyakarta. Block paraffin samples were cut $4 \mu \mathrm{m}$ in thickness to analyze the expression of p53 mutant, EGFR, CK5/6 and AR by using immunohistochemistry method. Antibody used in this study were Rabbit monoclonal Ab p53 mutant (Clone Ab 32049, dilution 1:50, Abcam, Massachusets, USA), mouse monoclonal Ab EGFR (Clone NCL-L-EGFR, dilution 1:20, Novocastra, Illinois, USA), mouse monoclonal Ab CK5/6 (Clone D5 \& 16B4, RTU, Cell Marque, California, USA), and mouse monoclonal Ab AR (Clone NC1-AR-318, dilution 1:50, Novocastra, Illinois, USA), with chromogen DAB. In this study, the membranous expression of CK 5/6 and EGFR in more than $10 \%$ of the tumor cells, the nuclei expression of AR in more than $5 \%$ of the tumor cells, and nuclei expression of $\mathrm{p} 53$ mutant in more than $1 \%$ of the tumor cells were considered positive.(9)

\section{Pathology Assessment}

All samples were evaluated independently by 2 senior pathologists. If there was any disagreement between the 2 pathologists, discussion was allowed and consensus had to be made between them. Basal-like characteristic was defined as tumor specimen which expressed EGFR and/or CK 5/6.

\section{Statistical Analysis}

Statistical analysis was performed using SPSS version 24 software (IBM Corporation, Armonk, New York, USA). Association between tumor subtype and clinicopathologic feature was analyzed using chi-square test or Fisher's exact test if assumptions for chi-square test were violated. All of the reported p-values are two-sided, with significance level set at $p<0.05$. Survival analysis was performed using Kaplan Meier curve. Overall survival (OS) was defined as duration between diagnosis until event (death) or the end of follow-up (30 months). Cutoff for OS analysis was set at 30 months.

\section{Results}

Out of 67 included subjects, 45 were classified into basallike subgroup dan 22 were classified into non-basal-like. The mean age of the subjects was 51 years old, while the median age was 50.16. Subjects were divided into 2 groups according to its median value, 33 (49.3\%) subjects were below 50 years old and $34(50.7 \%)$ subjects were more than or equal to 50 years old. Subjects in basal-like subgroup was significantly younger ( $57.8 \%$ of basal-like subgroup patients 
were classified into $<50$ years old category vs $42.2 \%$ in nonbasal-like group, $p<0.05)$. The mean and median BMI in this study were 24 . Forty (59.7\%) subjects had BMI $<25$ and 27 (40.3\%) subjects had BMI $\geq 25$. Non-basal-like subgroup has significantly higher BMI (63.7\% of non-basal-like patients had $\mathrm{BMI} \geq 25$ vs. $28.9 \%$ in basal-like group, $p<0.05$ ). Eleven (16.4\%) subjects presented with early stage (I-IIA), $44(65.7 \%)$ subjects presented with locally advanced stage (IIB-IIIC), while $12(17.9 \%)$ subjects presented with stage IV disease. Twenty (29.9\%) subjects presented with tumor size $(\mathrm{T})<5 \mathrm{~cm}$ while $47(70.1 \%)$ subjects presented with $\mathrm{T}$ $\geq 5 \mathrm{~cm}$. Forty-five $(67.2 \%)$ subjects presented with no nodal involvement $(\mathrm{N})$, while $22(32.8 \%)$ subjects had at least 1 nodal metastasis. The most commonly found histological type was infiltrating ductal, which was found in $55(82 \%)$ subjects, lobular type was found in $6(9 \%)$ subjects, while the remaining $6(9 \%)$ subjects had variable histological type. There was no significant difference in disease stage, tumor size, nodal status, as well as histological type between basallike and non-basal-like subjects. P53 mutant was positive in $30(44.8 \%)$ subjects with no significant difference between basal-like and non-basal-like subjects. Androgen receptor expression was found to be significantly higher in basallike subgroup $(p<0.05)$, with all $9(15 \%)$ AR expressing subjects were found in basal-like subgroup (20\% of basallike subjects) (Table 1, Figure 1).

Out of 67 patients included, 34 patients $(50.7 \%)$ were alive at 30-months follow up, while 33 patients (49.3\%) passed away. Twenty-seven patients passed away in the basal-like group, while 6 patients passed away the non-basal like group ( $60 \%$ vs. $21.4 \%$, respectively). The mean of OS in the basal-like group was 23.9 months (95\% CI: $21.9-25.9$

Table 1. Clinicopathologic profile of basal-like and non-basal-like TNBC.

\begin{tabular}{|c|c|c|c|}
\hline Parameter & $\begin{array}{c}\text { Basal-Like } \\
(n=45)\end{array}$ & $\begin{array}{l}\text { Non-Basal-Like } \\
\qquad(\mathrm{n}=\mathbf{2 2})\end{array}$ & $p$-value \\
\hline \multicolumn{4}{|l|}{ CK5/6 } \\
\hline Positive & 40 & 0 & \\
\hline Negative & 5 & 22 & \\
\hline \multicolumn{4}{|l|}{ EGFR } \\
\hline Positive & 28 & 0 & \\
\hline Negative & 17 & 22 & \\
\hline AR & & & $0.025^{*}$ \\
\hline Positive & 9 & 0 & \\
\hline Negative & 36 & 22 & \\
\hline p53 Mutant & & & 0.983 \\
\hline Positive & 20 & 10 & \\
\hline Negative & 25 & 12 & \\
\hline Type & & & 0.476 \\
\hline Ductal & 37 & 18 & \\
\hline Lobular & 3 & 3 & \\
\hline Other & 5 & 1 & \\
\hline Stage & & & 0.275 \\
\hline Early & 9 & 2 & \\
\hline Locally Advanced & 29 & 15 & \\
\hline Metastatic & 7 & 5 & \\
\hline Tumor Size & & & 0.373 \\
\hline$<5 \mathrm{~cm}$ & 15 & 5 & \\
\hline$\geq 5 \mathrm{~cm}$ & 30 & 17 & \\
\hline Nodal Status & & & 0.498 \\
\hline Positive & 16 & 6 & \\
\hline Negative & 29 & 16 & \\
\hline Distant Metastasis & & & 0.51 \\
\hline Present & 38 & 17 & \\
\hline Absent & 7 & 5 & \\
\hline Age & & & $0.046^{*}$ \\
\hline$<50$ y.o & 26 & 7 & \\
\hline$\geq 50$ y.o & 19 & 15 & \\
\hline BMI & & & $0.006^{*}$ \\
\hline$<25$ & 32 & 8 & \\
\hline$\geq 25$ & 13 & 14 & \\
\hline
\end{tabular}

* Chi-squared test and fisher exact test were used to analyze this table. 

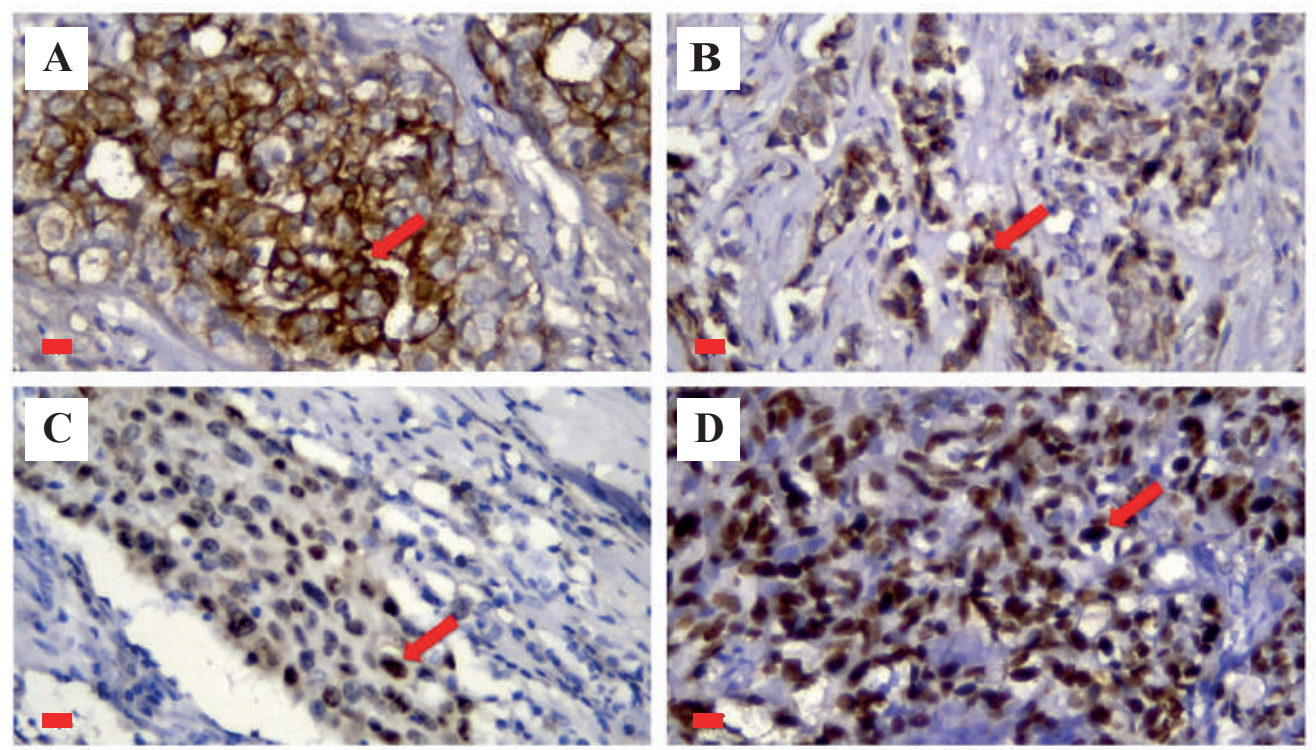

Figure 1. Immunohistochemistry staining result. A: CK 5/6 (red arrow points at positively stained in cytoplasmic membrane and cytoplasm of tumor cell); B: EGFR (red arrow points at positively stained in cytoplasmic membrane and cytoplasm of tumor cell); C: AR (red arrow points at positively stained in nucleus of tumor cell); D: p53 mutant (red arrow points at positively stained in nucleus of tumor cell). Red bar: $10 \mu \mathrm{m}$.

months), significantly shorter than non-basal-like subgroup of 26.1 months (95\% CI: 23-29.2 months; $p<0.05$ ) (Figure 2, Table 2). Median OS of basal-like subgroup was 25.4 months (95\% CI: 17.4-33.3 months), while median OS in non-basal-like subgroup was not yet reached.

\section{Discussion}

Studies showed that TNBC has general symptoms found in many diseases, and has diverse histopathological features. Some markers indicate poor prognosis, such as CK5/6 and EGFR, which were also found in the basal-like group. Aligned with other reports, our study also found that basallike subtype had poor prognosis with shorter OS and found in the younger patients.(9) The underlying mechanism is thought to be associated with the important role of EGFR in tumor cell proliferation, migration, invasiveness, as well as cellular survival.(10)
Basal-like subtpe can be further classified into subgroups of differing prognosis according to expression of numerous biomarkers, including AR dan p53 mutant. Interestingly, in this study we observed increased expression of AR in basal-like subgroup ( $20 \%$ in basal-like $v s .0 \%$ in non-basal-like; $15 \%$ in all study subjects). Androgen receptor is expressed in roughly $28 \%$ (12-53\%) of all TNBC cases. (11-15) The wide variability of reported AR expression in TNBC is considered due to the absence of standardized method of determining AR positivity. Although the exact role of AR in TNBC is not yet fully understood, several studies consider AR as a negative prognostic factor. $(8,16,17)$ Detrimental effect of AR is hypothesized by inducing cancer cell migration and invasiveness.(6) Vanderbilt classification considered AR+ TNBC as a separate entity (luminal androgen receptor (LAR) subtype) which had lower response rate towards systemic chemotherapy. (18) However, addition of androgen antagonist, including bicalutamide abiraterone acetate (AA) and enzalutamide, to

Table 2. Mean overall survival and survival rate at 30-months of basal-like and non-basal-like TNBC.

\begin{tabular}{|c|c|c|c|c|c|}
\hline \multirow{3}{*}{ Subtype } & \multicolumn{3}{|c|}{ Mean Survival (Months) } & \multicolumn{2}{|c|}{$\begin{array}{l}\text { Survival Rate at 30-Months } \\
\text { (n (\%)) }\end{array}$} \\
\hline & \multirow{2}{*}{ Estimate } & \multicolumn{2}{|c|}{$95 \%$ Confidence Interval } & \multirow{2}{*}{ Alive } & \multirow{2}{*}{ Deceased } \\
\hline & & Lower Bound & Upper Bound & & \\
\hline Basal-Like & 23.933 & 21.971 & 25.896 & $18(40)$ & $27(60)$ \\
\hline Non-Basal-Like & 26.109 & 23.024 & 29.194 & $16(72.7)$ & $6(27.3)$ \\
\hline Overall & 24.648 & 22.967 & 26.328 & $34(50.7)$ & $33(49.3)$ \\
\hline
\end{tabular}




\section{Survival Functions}
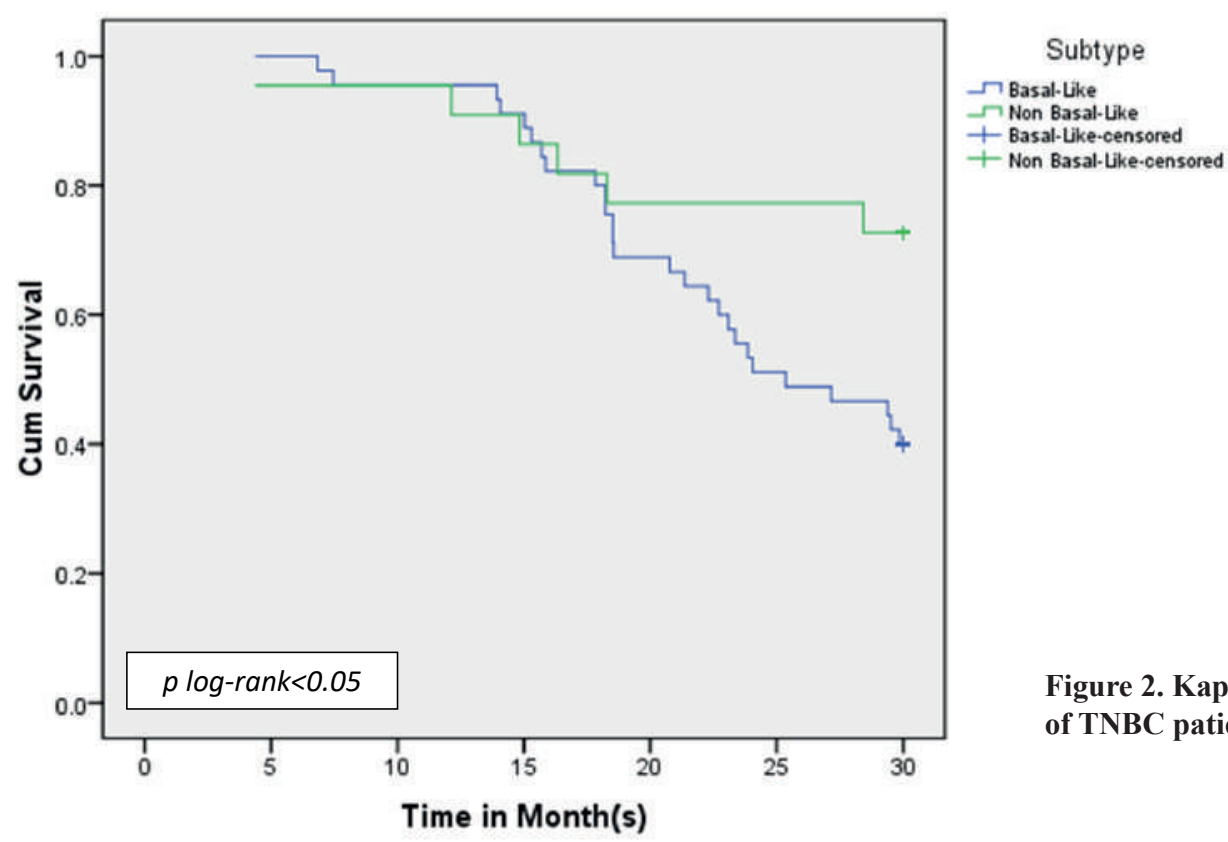

Figure 2. Kaplan-meier overall survival curve of TNBC patients according to subtypes.

$\mathrm{AR}+\mathrm{TNBC}$ patients have shown positive clinical response, which might serve as potential treatment modality. $(13,19,20)$ To understand which patient might gain the most benefit from anti-androgen therapy, previous study stratified TNBC into 3 risk groups according to AR and EGFR expression. The best prognosis was observed in AR+ EGFR- (represents LAR subtype) which may benefit the most from anti-androgen therapies; worse prognosis was observed in AR- EGFR+ (represents the basal-like subtype) which may benefit the most from chemotherapy regimens; and intermediate prognosis in AR+ EGFR+ and AR- EGFRTNBC.(16) Expression of p53 mutant is known to be prevalent in all of breast cancer and has been reported to be associated more aggressive tumor characteristic, including expression of basal-like markers (EGFR and CK5/6). (21) However, in this study we observed no significant association between basal-like subtype and p53 mutant expression. Expression of p53 mutant in our study was found in 30 subjects $(44.8 \%)$, which is considerably lower than previously reported by other studies (64-82\%).(7,22$25)$ This discrepancy is thought to be influenced by race and genetic as p53 mutant is known to be expressed higher in African-American women and in early onset breast cancer ( $\leq 35$ years old), as well as in women with familial history of breast cancer, which is considerably different with our cohort of Indonesian patients with mean age of 51 years old. $(26,27)$ The only clinical feature with significant difference between basal-like and non-basal-like subtype in our study is BMI, which higher proportion of subject with $\mathrm{BMI} \geq 25$ is observed in non-basal-like subtypes ( $63.7 \%$ vs. $28.9 \%$, $p<0.05)$. Higher BMI is known to be associated with luminal breast cancer due to the interaction between adipose tissue with hormonal receptors. As such, proportion of patients with $\mathrm{BMI}<25$ is usually higher in TNBC when compared to luminal type.(28) However, there are other roles of adipose tissue in carcinogenesis of breast cancer, including increased pro-inflammatory cytokines, increased mammalian target of rapamycin (mTOR) activation, and alteration of tumor microenvironment, which might explain the increased risk of developing TNBC in women with obesity.(29) The higher BMI observed in our non-basal-like subjects might suggest different process of metabolic carcinogenesis between these 2 subtypes.(30)

This study has several limitations. Our study was a retrospective cohort study with limited sample size, thus further prospective study with bigger sample size and longer follow up period to validate its result is required. We performed analysis of overall survival at 30 months, which is considered as short-term compared to the more commonly reported of 5-years overall survival.

\section{Conclusion}

In a cohort of 67 Indonesian TNBC patients, basal-like subtype is associated with shorter overall survival, younger age at diagnosis and higher frequency of AR expression, while non-basal-like subtype is associated with higher BMI. 


\section{Acknowledgements}

The authors express the upmost gratitude towards Professor Iwan Dwiprahasto who recently passed away due to Covid-19, for his massive contribution not only towards this research but also towards Indonesian health service and education.

\section{References}

1. Wahidin M, Noviani R, Hermawan S, Andriani V, Ardian A, Djarir H. Population-based cancer registration in Indonesia. Asian Pacific J Cancer Prev. 2012; 13: 1709-10.

2. Bray F, Ferlay J, Soerjomataram I, Siegel RL, Torre LA, Jemal A. Global cancer statistics 2018: GLOBOCAN estimates of incidence and mortality worldwide for 36 cancers in 185 countries. CA Cancer J Clin. 2018; 68: 394-424

3. Carey L, Winer E, Viale G, Cameron D, Gianni L. Triple-negative breast cancer: disease entity or title of convenience? Nat Rev Clin Oncol. 2010; 7: 683-92.

4. Perou CM, Sørlie T, Eisen MB, van de Rijn M, Jeffrey SS, Rees CA, et al. Molecular portraits of human breast tumours. Nature. 2000; 406: 747-52.

5. Purwanto I, Dwiprahasto I, Aryandono T, Haryana SM. Treatment options for Indonesian triple negative breast cancer patients: a literature review of current state and potentials for future improvement. J Med Sci. 2020; 52: 81-101.

6. Giovannelli P, Di Donato M, Auricchio F, Castoria G, Migliaccio A. Androgens induce invasiveness of triple negative breast cancer cells through AR/Src/PI3-K complex assembly. Sci Rep. 2019; 9: 4490.

7. Coradini D, Biganzoli E, Ardoino I, Ambrogi F, Boracchi P, Demicheli $\mathrm{R}$, et al. p53 status identifies triple-negative breast cancer patients who do not respond to adjuvant chemotherapy. Breast. 2015; 24 : 294-7.

8. Dieci MV, Tsvetkova V, Griguolo G, Miglietta F, Mantiero M, Tasca $\mathrm{G}$, et al. Androgen receptor expression and association with distant disease-free survival in triple negative breast cancer: analysis of 263 patients treated with standard therapy for stage I-III disease. Front Oncol. 2019; 9: 452. doi: 10.3389/fonc.2019.00452.

9. Carey LA, Perou CM, Livasy CA, Dressler LG, Cowan D, Conway K. Race, breast cancer subtypes, and survival in the Carolina Breast Cancer Study. JAMA. 2006; 295: 2492-502.

10. Abdelrahman AE, Rashed HE, Abdelgawad M, Abdelhamid MI. Prognostic impact of EGFR and cytokeratin 5/6 immunohistochemical expression in triple-negative breast cancer. Ann Diagn Pathol. 2017; 28: 43-53.

11. Chottanapund S, Van Duursen MBM, Ratchaworapong K, Navasumrit P, Ruchirawat M, Van den Berg M. Androgen receptor expression in Thai breast cancer patients. Med Sci (Basel). 2016; 4: 15. doi: 10.3390/medsci4030015.

12. Thike AA, Chong LYZ, Cheok PY, Li HH, Yip GWC, Bay BH, et al. Loss of androgen receptor expression predicts early recurrence in triple-negative and basal-like breast cancer. Mod Pathol. 2014; 27: 352-60.

13. Qi JP, Yang YL, Zhu H, Wang J, Jia Y,1 Liu N, et al. Expression of the androgen receptor and its correlation with molecular subtypes in 980 chinese breast cancer patients. Breast Cancer (Auckl). 2012; 6: 1-8. doi: 10.4137/BCBCR.S8323.
14. Gucalp A, Tolaney S, Isakoff SJ, Ingle JN, Liu MC, Carey LA, et al. Phase II trial of bicalutamide in patients with androgen receptorpositive, estrogen receptor-negative metastatic breast cancer. Clin Cancer Res. 2013; 19: 5505-12.

15. Xu M, Yuan Y, Yan P, Jiang J, Ma P, Nio X, et al. Prognostic significance of androgen receptor expression in triple negative breast cancer: a systematic review and meta-analysis. Clin Breast Cancer. 2020; 20: e385-96.

16. Astvatsaturyan K, Yue Y, Walts AE, Bose S. Androgen receptor positive triple negative breast cancer: clinicopathologic, prognostic, and predictive features. PLoS One. 2018; 13(6): e0197827. doi: 10.1371/journal.pone.0197827.

17. Choi JE, Kang SH, Lee SJ, Bae YK. Androgen receptor expression predicts decreased survival in early stage triple-negative breast cancer. Ann Surg Oncol. 2015; 22: 82-9.

18. Masuda H, Baggerly KA, Wang Y, Zhang Y, Gonzalez-Angulo AM, Meric-Bernstam F, et al. Differential response to neoadjuvant chemotherapy among 7 triple-negative breast cancer molecular subtypes. Clin Cancer Res. 2013; 19: 5533-40.

19. Bonnefoi H, Grellety T, Tredan O, Saghatchian M, Dalenc F, Mailliez A, et al. A phase II trial of abiraterone acetate plus prednisone in patients with triple-negative androgen receptor positive locally advanced or metastatic breast cancer (UCBG 12-1). Ann Oncol. 2016; $27: 812-8$.

20. Traina TA, Miller K, Yardley DA, Eakle J, Schwartzberg LS, O'Shaughnessy J, et al. Enzalutamide for the treatment of androgen receptor-expressing triple-negative breast cancer. J Clin Oncol. 2018; 36: 884-90.

21. Abubakar M, Guo C, Koka H, Sung H, Shao N, Guida J, et al. Clinicopathological and epidemiological significance of breast cancer subtype reclassification based on p53 immunohistochemical expression. NPJ Breast Cancer. 2019; 5: 20. doi: 10.1038/s41523019-0117-7.

22. The Cancer Genome Atlas Network. Comprehensive molecular portraits of human breast tumors. Nature. 2012; 490: 61-70.

23. Biganzoli E, Coradini D, Ambrogi F, Garibaldi JM, Lisboa P, Soria $\mathrm{D}$, et al. $\mathrm{p} 53$ status identifies two subgroups of triple-negative breast cancers with distinct biological features. Jpn J Clin Oncol. 2011; 41: 172-9.

24. Walerych D, Napoli M, Collavin L, Del Sal G. The rebel angel: mutant p53 as the driving oncogene in breast cancer. Carcinogenesis. 2012; 33: 2007-17.

25. Millis SZ, Gatalica Z, Winkler J, Vranic S, Kimbrough J, Reddy S, et al. Predictive biomarker profiling of $>6000$ breast cancer patients shows heterogeneity in TNBC, with treatment implications. Clin Breast Cancer. 2015; 15: 473-481.e3.

26. Lee DS, Yoon SY, Looi LM, Kang P, Kang IN, Sivanandan K, et al. Comparable frequency of BRCA1, BRCA2 and TP53 germline mutations in a multi-ethnic Asian cohort suggests TP53 screening should be offered together with BRCA1/2 screening to early-onset breast cancer patients. Breast Cancer Res. 2012; 14: R66.

27. Dookeran KA, Dignam JJ, Holloway N, Ferrer K, Sekosan M, McCaskill-Stevens W, et al. Race and the prognostic influence of p53 in women with breast cancer. Ann Surg Oncol. 2012; 19: 233444.

28. Babu KG, Anand A, Laksmaiah KC, Lokanatha D, Jacob LA, Babu MS, et al. Correlation of BMI with breast cancer subtype and tumour size. Ecancermedicalscience. 2018; 12: 845.

29. Dietze EC, Chavez TA, Seewaldt VL. Obesity and triple-negative breast cancer. Am J Pathol. 2018; 188: 280-90.

30. Sun X, Wang M, Wang M, Yu X, Guo J, Sun T, et al. Metabolic reprogramming in triple-negative breast cancer. Front Oncol. 2020; 10: 428. doi: 10.3389/fonc.2020.00428. 